\title{
The importance of having the opportunity to communicate with the dentist, from the patient's perspective
}

\author{
Lucian Josan', Simona Ioana Josan', Paul Ioan Nandrean' ${ }^{1}$ Cristian Olteanu², \\ Ana Petra Lazar ${ }^{3}$, Dan Serbanoiu ${ }^{3}$, Alexandru Zalana², Mariana Pacurar ${ }^{3}$ \\ ${ }^{1} \mathrm{CMI}$ Dr. Lucian Josan, Alba Iulia \\ 2Orthodontics Department, Faculty of Dental Medicine, "Iuliu Hatieganu" \\ University of Medicine and Pharmacy, Cluj-Napoca \\ ${ }^{3}$ Orthodontics Department, Faculty of Dental Medicine, UMFST Tg. Mures
}

\begin{abstract}
Most medical acts have, as a common and necessary element, the communication between the doctor and the patient, which considerably increases the quality of the interaction between them. The patient needs to understand the importance of having the opportunity to talk to the dentist.

The present statistical study was conducted on 194 subjects (113 female subjects and 81 male subjects), aged between 20 and 50 years, in two dental practices: one in Alba lulia and the other in Tg. Mures. The purpose is to determine the patients' qualities, from the following perspectives: good or poor listener, compliant, obedient, having efficient or inefficient communicating skills. The subjects of the study were asked a set of questions from a questionnaire which highlights the confirmation or dismissal of the proposed objectives. The results will show us to what extent the patients appreciate the opportunity to communicate with the dentist. At the same time, the patients' qualities which recommend them as participants in an optimal communication process will be highlighted.
\end{abstract}

Keywords: communication opportunity, patient compliance / adherence, efficient / inefficient communication

\section{INTRODUCTION}

Communication with patients is an essential part of most medical acts.

It is recommended that the doctor offers the patient the opportunity to communicate with him all the time about therapeutic possibilities, prognosis and the best moment to start a treatment. It is necessary that the doctor should be empathetic, honest, respectful and highly rigorous about his interactions with the patient. In the process of communication, one can say that there takes place something that can be illustrated as follows:

What I'm thinking $\rightarrow$ What I mean $\rightarrow$ What I'm saying $\rightarrow$ What you hear $\rightarrow$ What you are listening to $\rightarrow$ What you understand (9)
Through communication, we obtain from the patient the following:

Compliance - designates the concordance between therapeutic prescriptions and the patient's behaviour, which defines the ability to follow some therapeutic prescriptions (it is also called adherence).

Adherence - implies an active participation on the patient's part, whereas compliance means a passive submission to medical recommendations.

Getting to like each other - the fact that two interlocutors, even in a medical practice (doctor - patient) like each other contributes to the process of obtaining high quality information. Adapting language to the patient's level of understanding leads to a closer communication between the two persons 
involved, leading to the felicitous state in which the doctor obtains the patient's trust.

Gaining the patient's trust - this aspect is very important for a successful treatment and for the professional relationship between doctor and patient. The patient needs to trust the doctor, to be convinced that he or she will find a solution to his problem, not to suspect him of making mistakes. Moreover, two persons who like each other cooperate better with each other.

Another important element in the interaction between doctor and patient is the ability for empathy of the healthcare provider.

Obtaining empathy - empathy is the complete openness to the other's experience, to his or her way of thinking or feeling; the doctor needs to be congruent, responsive (10).

Adaptability - implies the possibility to redistribute our resources and skills, with one single object in mind, that of survival (3).

The doctor is aware of the necessity to apply adaptability in his or her relationship with the patient and should seek to obtain this from the patient as well. Through his or her interaction with the patient, the doctor is also confronted with emotional transference.

Self-efficacy - the conviction that a person uses his or her abilities and interacts accordingly, in order to reach a clear objective (1) - is an indicator of involvement.

Routine - the ability gained through long practice, the habit to always act or think in the same way; the sum of habits or prejudices considered to be an obstacle to novelty, creation or progress. In his or her interactions with the patient, the doctor meets good or poor listeners.

A patient who is a good listener is patient, maintains eye contact with the doctor, looking at him in a relaxed, but attentive manner. He or she participates in the dialogue, giving the doctors answers which can contribute to the therapeutic behaviour, is patient, and does not interrupt the doctor. A patient who is a good listener is focused on the subject and asks the doctor's opinions.

A patient who is a poor listener - an attitude that the doctor frequently encounters - has the tendency to change the subject all the time, avoids eye contact, is impatient and shows distrust, and wants to be the one who does all the talking. He or she does not wait to receive answers from the doctor; his or her attention is constantly distracted, does not contribute to anamnesis, because he or she does not provide clear answers, or asks closed questions (8).

In the case of doctor-patient communication, there are two options:

- Efficient communication, which represents the open and direct expression of feelings and encouraging the partner / patient to do the same (7);

- Inefficient communication: the truth belongs to me, and the existing problem is caused by the other's mistake (2). In this type of communication, the patient manifests a demanding attitude - the subject claims that he or she has the right to a better treatment, and employs sarcasm (the tone of voice betrays tension and hostility).

The main objective of the present study is to highlight the importance of the communication with the dentist, from the patient's perspective.

\section{Secondary objectives:}

A. highlighting certain qualities in the patient (good or poor listener);

B. compliant/adherent patient, from a behavioural point of view;

C. patients who communicate in an efficient or inefficient way;

\section{MATERIAL AND METHOD}

The study was conducted on 194 subjects (113 female subjects and 81 male subjects), over a period of 8 months, that is: 1 January $2018-31$ August 2018.

The subjects were divided into 6 age categories (both the female and the male ones) as follows: $15-19$ years, 20-29 years, 30-39 years, $40-49$ years, 50-59 years and over 60 years.

The criteria for inclusion in the study:

- the subjects frequented the dental practice at least once, as patients;

- the subjects were cooperative.

The criteria for exclusion from the study:

- the subjects who frequented the dental practice as patients, but refused to fill in the questionnaire.

The questionnaire given to the patients encompassed 20 questions, structured as follows:

- 6 pairs (12 questions) about the importance of communication; 
- 1 pair (2 questions) about highlighting the qualities of good / poor listener in the patient;

- 2 pairs (4 questions) about patient's compliance;

- 1 pair (2 questions) about the effectiveness of communication.

The use of the questions in this crossed manner helped us bring into relief the patients who stick to their options and the patients who change the option expressed before. The change of the option expressed before invalidates the answer, which would impede the fulfilment of the objective.

\section{RESULTS}

The questionnaires were applied to a number of 194 subjects, of whom 113 subjects were female and 81 , male. The distribution of the subjects according to gender and age group is illustrated in Figure 1 below.

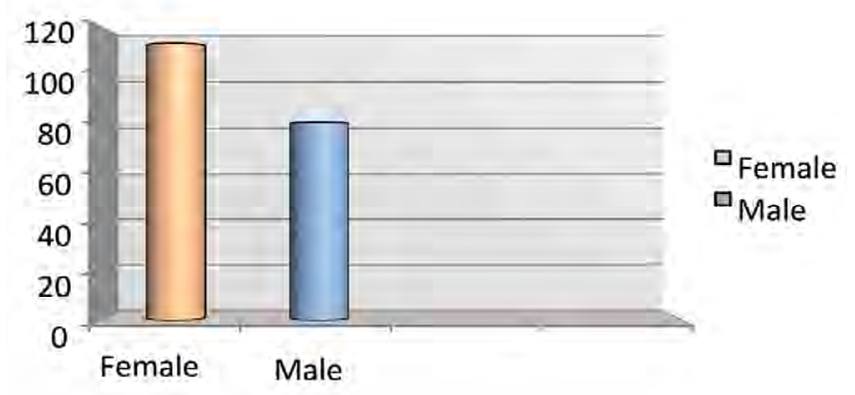

FIGURE 1. Distribution of subjects according to gender

\section{Female patients}

15-19 years: 3 subjects

20-29 years: 25 subjects

30-39 years: 27 subjects

40-49 years: 27 subjects

50-59 years: 19 subjects

over 60 years: 12 subjects
There is a predominance of patients with the age between 30 and 49 years, who manifest good compliance and a constant willingness to communicate with the dentist.

\section{Male patients}

15-19 years: 7 subjects

20-29 years: 11 subjects

30-39 years: 15 subjects

40-49 years: 24 subjects

50-59 years: 14 subjects

over 60 years: 10 subjects

In the case of male patients, the maximum number of responsive patients belongs to the same age group, 30-49 years, as illustrated in Figure 3.

For the female gender, the results according to age group are as follows:

The age group 15-19 years, female gender, confirms:

- $83.33 \%$, objective 1 - primary (appreciates and understands the importance of communication).

- $66.67 \%$ objective $2 \mathrm{~A}$ - secondary (patients who are good listeners).

- $66.67 \%$ objective $2 \mathrm{~B}$ - secondary (compliant, adherent patients).

- $100 \%$ objective $2 \mathrm{C}$ - secondary (patients who communicates efficiently).

The age group 20-29 years, female gender, confirms:

- $75.33 \%$ objective 1 - primary (appreciates and understands the importance of communication).

- $64 \%$ objective $2 \mathrm{~A}$ - secondary (patients who are good listeners).

- 66\% objective 2B - secondary (compliant, adherent patients).

- $60 \%$ objective $2 \mathrm{C}$ - secondary (patients who communicates efficiently).

The age group 30-39 years, female gender, confirms:

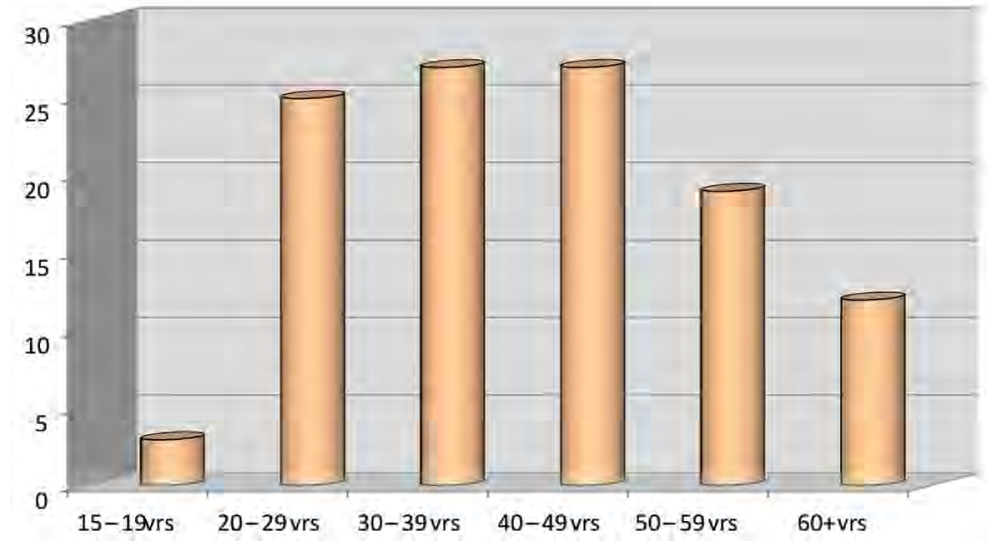

FIGURE 2. Distribution of female subjects, according to age group 


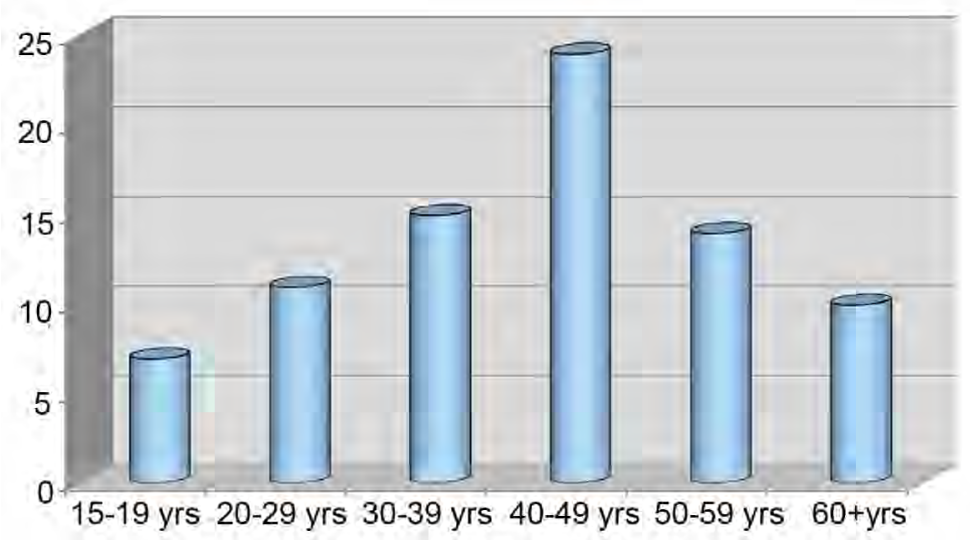

FIGURE 3. Distribution of male subjects according to age

- 75.93\% objective 1 - primary (appreciates and understands the importance of communication).

- $77.78 \%$ objective $2 \mathrm{~A}$ - secondary (patients who are good listeners).

- $88.89 \%$ objective $2 \mathrm{~B}$ - secondary (compliant, adherent patients).

- 55.56\% objective 2C - secondary (patients who communicates efficiently).

The age group 40-49 years, female gender, confirms:

- $84.57 \%$ objective 1 - primary (appreciates and understands the importance of communication).

- $88.89 \%$ objective $2 \mathrm{~A}$ - secondary (patients who are good listeners).

- $90.74 \%$ objective $2 \mathrm{~B}$ - secondary (compliant, adherent patients).

- 55.56\% objective 2C - secondary (patients who communicates efficiently).

The age group 50-59 years, female gender, confirms:
- $66.67 \%$ objective 1 - primary (appreciates and understands the importance of communication).

- $84.21 \%$ objective $2 \mathrm{~A}$ - secondary (patients who are good listeners).

- $76.32 \%$ objective $2 \mathrm{~B}$ - secondary (compliant, adherent patients).

- $36.84 \%$ objective 2C - secondary (patients who communicates efficiently).

The age group over 60 years, female gender, confirms:

- $84.72 \%$ objective 1 - primary (appreciates and understands the importance of communication).

- $83.33 \%$ objective $2 \mathrm{~A}$ - secondary (patients who are good listeners).

- $87.5 \%$ objective $2 \mathrm{~B}$ - secondary (compliant, adherent patients).

- $66.67 \%$ objective $2 \mathrm{C}$ - secondary (patients who communicates efficiently).

These results, expressed in percentages, are illustrated in Table 1 and in Figure 4.

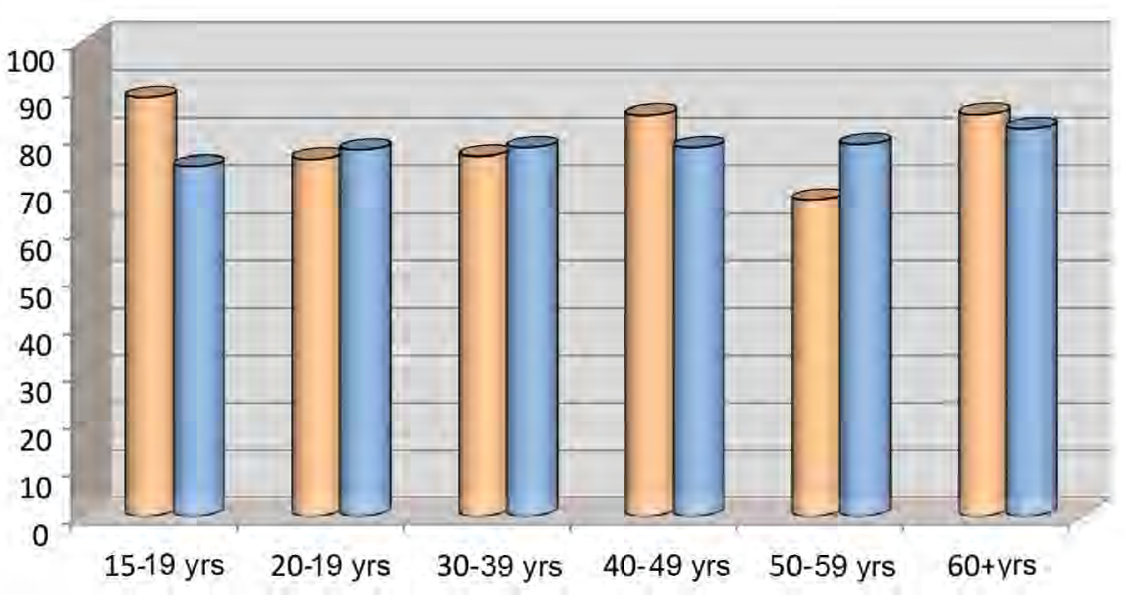

$\square \mathrm{F}$

$\square \mathrm{M}$

FIGURE 4. Level of confirmation of the primary objective, applied according to age groups 
TABLE 1. Proportional representation of objective confirmation

\begin{tabular}{|l|c|c|c|c|c|c|c|c|c|c|c|c|}
\hline No. & 1 & 2 & 3 & 4 & 5 & 6 & 7 & 8 & 9 & 10 & 11 & 12 \\
\hline Ob. 1 & 83.33 & 100 & 66.67 & 83.33 & 100 & 83.33 & 83.33 & 66.67 & 50 & 66.67 & 100 & 50 \\
\hline Ob. 2A & 0 & 100 & 100 & 100 & 100 & 100 & 100 & 100 & 100 & 100 & 100 & 0 \\
\hline Ob. 2B & 100 & 100 & 50 & 100 & 100 & 100 & 0 & 100 & 50 & 0 & 50 & 50 \\
\hline Ob. 2C & 0 & 100 & 100 & 0 & 100 & 100 & 100 & 0 & 0 & 0 & 0 & 0 \\
\hline Total & 45.83 & 100 & 79.17 & 70.83 & 100 & 95.83 & 70.83 & 66.67 & 50 & 41.67 & 62.5 & 25 \\
\hline 13 & 14 & 15 & 16 & 17 & 18 & 19 & 20 & 21 & 22 & 23 & 24 & Total sub/ob \\
\hline 100 & 33.33 & 83.33 & 83.33 & 83.33 & 66.67 & 100 & 83.33 & 33.33 & 100 & 83.33 & 100 & 78.47 \\
\hline 100 & 0 & 100 & 100 & 100 & 100 & 100 & 0 & 100 & 100 & 100 & 100 & 83.33 \\
\hline 100 & 100 & 100 & 100 & 50 & 100 & 100 & 0 & 50 & 100 & 50 & 100 & 72.92 \\
\hline 0 & 0 & 0 & 0 & 0 & 0 & 100 & 100 & 0 & 100 & 0 & 100 & 37.5 \\
\hline 75 & 33.33 & 70.83 & 70.83 & 58.33 & 66.67 & 100 & 45.83 & 45.83 & 100 & 58.33 & 100 & 68.05 \\
\hline
\end{tabular}

In the case of male subjects, the results are as follows (and they are structured in Figures 5, 6 and 7).

The age group 15-19 years confirms:

- 73.81\% objective 1 - primary (appreciates and understands the importance of communication).

- $85.71 \%$ objective $2 \mathrm{~A}$ - secondary (patients who are good listeners).

- $57.14 \%$ objective $2 \mathrm{~B}$ - secondary (compliant, adherent patients).

- $42.86 \%$ objective $2 \mathrm{C}$ - secondary (patients who communicates efficiently).

The age group 20-29 years confirms:

- 77.27\% objective 1 - primary (appreciates and understands the importance of communication).

- $72.73 \%$ objective $2 \mathrm{~A}$ - secondary (patients who are good listeners).

- $68.18 \%$ objective $2 \mathrm{~B}$ - secondary (compliant, adherent patients).

- $45.45 \%$ objective 2C - secondary (patients who communicates efficiently).

The age group 30-39 years confirms:

- 77.78\% objective 1 - primary (appreciates and understands the importance of communication).

- 53.33\% objective 2A - secondary (patients who are good listeners).

- $66.67 \%$ objective $2 \mathrm{~B}$ - secondary (compliant, adherent patients).

- 53.33\% objective 2C - secondary (patients who communicates efficiently).

The age group 40-49 years confirms:

- $77.78 \%$ objective 1 - primary (appreciates and understands the importance of communication).
- $87.5 \%$ objective $2 \mathrm{~A}$ - secondary (patients who are good listeners).

- $79.17 \%$ objective $2 \mathrm{~B}$ - secondary (compliant, adherent patients).

- $41.67 \%$ objective 2C - secondary (patients who communicates efficiently).

The age group 50-59 years confirms:

- $78.47 \%$ objective 1 - primary (appreciates and understands the importance of communication).

- $83.33 \%$ objective $2 \mathrm{~A}$ - secondary (patients who are good listeners).

- $72.92 \%$ objective $2 \mathrm{~B}$ - secondary (compliant, adherent patients).

- 37.5\% objective 2C - secondary (patients who communicates efficiently).

The age group of over 60 confirms:

- $81.67 \%$ objective 1 - primary (appreciates and understands the importance of communication).

- $90 \%$ objective $2 \mathrm{~A}$ - secondary (patients who are good listeners).

- $85 \%$ objective $2 \mathrm{~B}$ - secondary (compliant, adherent patients).

- $50 \%$ objective $2 \mathrm{C}$ - secondary (patients who communicates efficiently).

\section{DISCUSSIONS}

The fact that, according to our study, in the $21^{\text {st }}$ century, $20-22 \%$ of the subjects do not appreciate the importance of having the opportunity to communicate with the dentist shows that, in the process of interaction between doctor and patient, there is not enough emphasis on communication and on all the elements that constitute this concept. As regards 


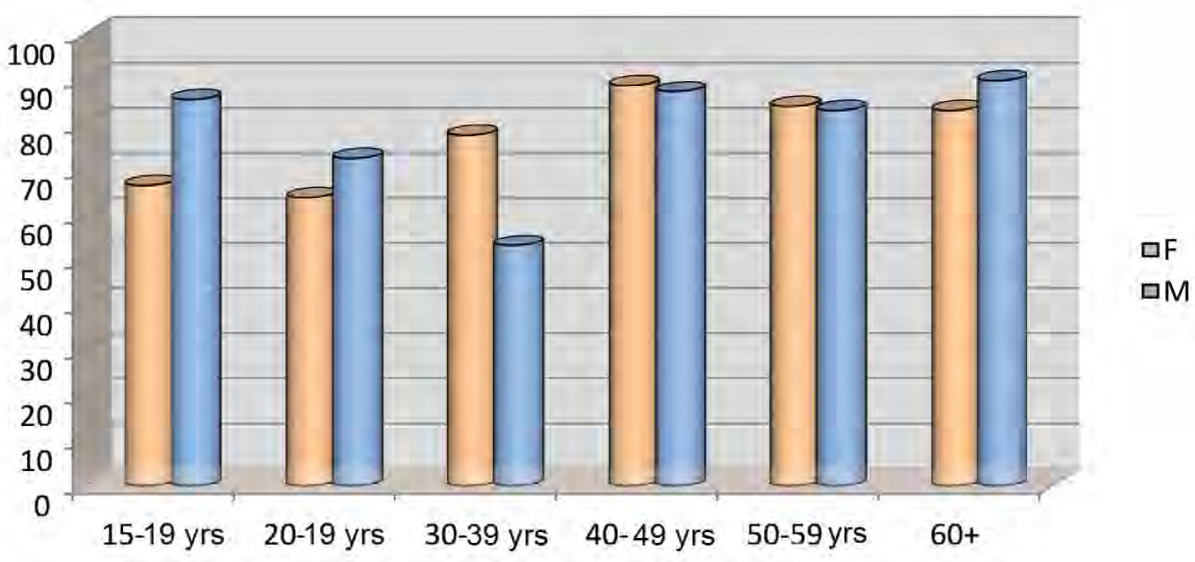

FIGURE 5. Proportional representation of confirmation of objective 2

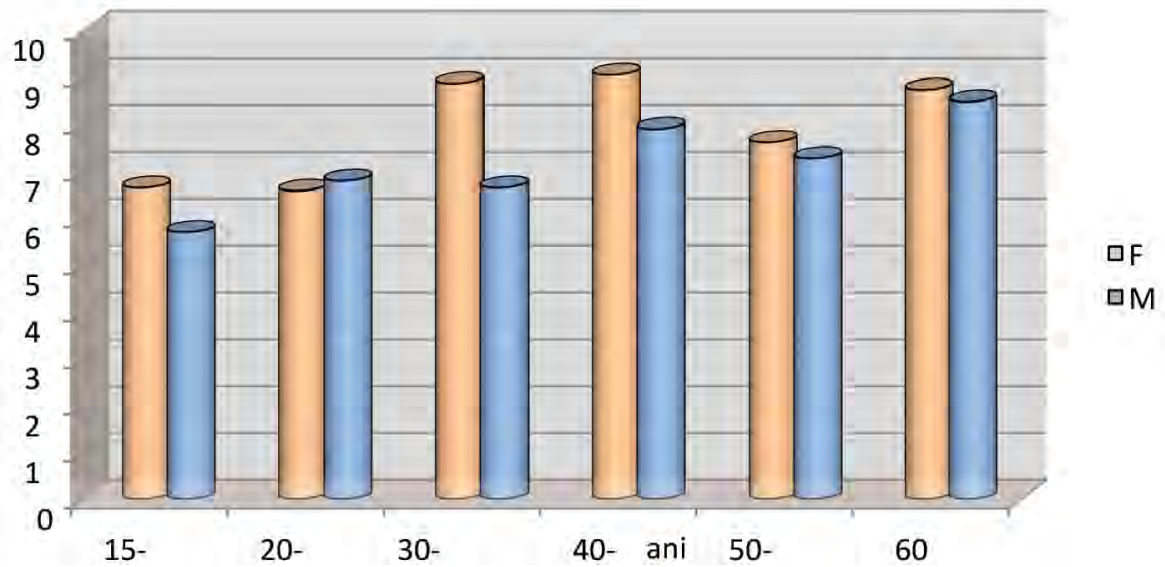

FIGURE 6. Proportional representation of confirmation of objective $2 B$

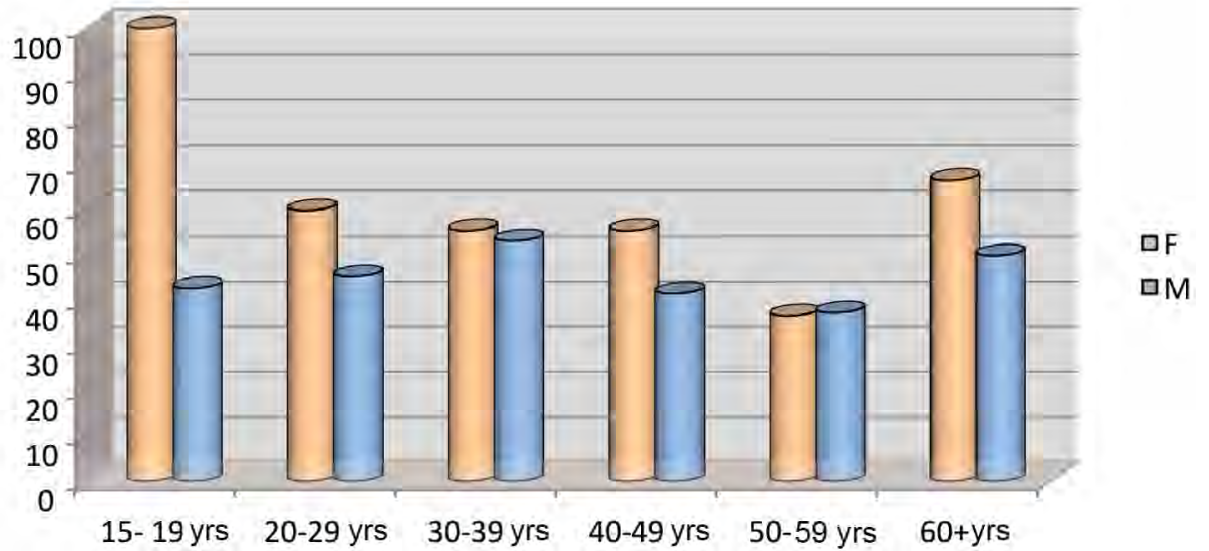

FIGURE 7. Proportional representation of confirmation of objective $2 C$

the aspect of good listener vs. bad listener in patients, the fact that the rate is of $22 \%$ in the case of both genders and of patients who are poor listeners makes us feel optimistic about the future and hope for its decrease. The percentage which impedes reaching the compliance and adherence objectives in the subjects shows that female patients are more compliant, in comparison with male subjects, as Dumitrascu, Păcurar $(5,11)$ also observed.

As regards the efficacy of communication, the percentage which does not confirm the objective is higher in the case of male subjects and lower in the 
case of female subjects. Female subjects communicate more efficiently; it might be possible that a more ample implementation of elements which are necessary for communication can help male patients improve this aspect. The literature confirms the fact that patients appreciate communication, and this aspect is validated by our study as well. According to Pasca M. and Radu N. $(9,10)$, there are certain barriers which impede a successful communication between doctor and patients.

Barriers created by doctors are represented by: wasted time, tiredness, loss of control over important elements of anamnesis, the inability to empathise. Barriers created by patients are represented by: the attempt to dissimulate when it comes to manifesting their inner feelings, avoiding the possibility of finding themselves in an unpleasant situation, the fear of being sick $(7,8)$. Successful communication depends on the doctor's experience and personality, as well as on the intellectual level of the patient, on the duration of the interaction between the two parties, on maintaining eye contact until the end of the encounter, while failed communication is caused by a patient's lack of trust $(1,2)$.

As regards the objective about appreciating and understanding the importance of communication in the interaction with a dentist, the average of the values obtained in all age groups is $78.42 \%$ in the case of female subjects and $77.8 \%$ in the case of male subjects; the rates which indicate an absence of the willingness to communicate are: $21.58 \%$ (female gender) and 22.2\% (male gender).

\section{CONCLUSIONS}

1. The age groups $\mathbf{1 5 - 1 9}$ years, 20-29 years and 30-39 years, female gender, appreciate, in a high proportion $(83.33 \% \%)$ the importance of communicating with the dentist. The subjects from these categories are good listeners and compliant, in a percentage that exceeds the average, and they communicate efficiently with the dentist.

\section{REFERENCES}

1. Bandura A. Autoefficacia - Teoria e applicazioni. Editura Erickson, 2000.

2. Burns D. The Feeling Good Handbook. A Plume Book, New York, 1989

3. Coleman V. Puterea trupului - Cum să ne păstrăm sănătatea si vigoarea. Editura Polimark, Bucureşti, 1995.
2. The age group 40-49 years, female gender, appreciates in a higher proportion than the previous categories $(84.57 \%)$ the importance of communicating with the dentist, being better listeners and compliant in a percentage that slightly exceeds the one of the categories above.

3. The age group 50-59 years, female gender, appreciates in a smaller proportion the importance of communicating with the dentist. The subjects are good listeners and compliant in a smaller percentage compared with the category above

4. The age group of over 60 years, female gender, appreciates in a higher proportion the importance of communicating with the dentist (a higher percentage than the agre groups 15-19 years and 40-49 years). The subjects from this category are better listeners and more compliant in a very high percentage.

5 The age groups 15-19 years, 20-29 years, 3039 years and 40-49 years, male gender, appreciate in a high proportion the importance of communicating with the dentist, being good listeners in a higher proportion and compliant only in a percentage that slightly exceeds the average.

6. The age group 50-59 years, male gender, appreciates the importance of communication in a lower proportion (good listeners and compliant in a lower percentage, compared with the other categories).

7. In the case of the age group of over 60 years, male gender, we noticed the fact that they appreciate the importance of communicating with the dentist in the highest proportion, being good listeners and compliant.

8. For all the age groups, related to all the four objectives, the female patients appreciate in a higher proportion the importance of communicating with the dentist than the male subjects, the biggest difference being at the age group 15-19 years.

4. Dumitraşcu DL. Comunicare medicală. Editura Medicală Universitară Iuliu Haţieganu, Cluj-Napoca, 2013.

5. Dumitraşcu DL. Medicina psihosomatică. Editura Medicală Universitară luliu Haţieganu, Ediţia a II-a, Cluj-Napoca, 2013.

6. Egner B. Emplatly in Feldman MD, Christensen JF. Behavioural Medicine in Primary. 1997. 
7. Holdevici I. Ameliorarea performantelor individuale prin tehnici de psihoterapie. Editura Orizonturi, Bucureşti, 2000.

8. Josan L. Alte aspecte ale comportamentului pacientilor în cabinetul dentar - psihosomatică si comunicare, Editura Aeternitas, Alba Iulia, 2018.

9. Paşca MD. Comunicarea în relatia medic-pacient. Ed. University Press, Târgu Jiu, 2012.
10. Radu N. Dirijarea comportamentului uman, Editura Albatros, Bucureşti, 1981.

11. Nimigean V, Păcurar M. Abordarea psihologică a adolescentului şi adultului tânăr. Editura Tehnoplast, Bucureşti, 2003. 